\title{
Multilevel-analysis identify a cis-expression quantitative trait locus associated with risk of renal cell carcinoma
}

\author{
Xiang Shu ${ }^{1, *}$, Mark P. Purdue ${ }^{2,}{ }^{,}$, Yuanqing Ye ${ }^{1}$, Christopher G. Wood $^{3}$, Meng Chen ${ }^{1}$, \\ Zhaoming Wang ${ }^{4}$, Demetrius Albanes ${ }^{2}$, Xia $\mathrm{Pu}^{1}$, Maosheng Huang ${ }^{1}$, Victoria $\mathrm{L}$. \\ Stevens $^{5}$, W. Ryan Diver ${ }^{5}$, Susan M. Gapstur ${ }^{5}$ Jarmo Virtamo ${ }^{6}$, Wong-Ho Chow $^{1}$, \\ Nizar M. Tannir ${ }^{7}$, Colin P. Dinney ${ }^{3}$, Nathaniel Rothman ${ }^{2}$, Stephen J. Chanock ${ }^{2, *}$, \\ Xifeng $\mathbf{W u}^{1, *}$ \\ ${ }^{1}$ Department of Epidemiology, The University of Texas MD Anderson Cancer Center, Houston, Texas, USA \\ ${ }^{2}$ Division of Cancer Epidemiology and Genetics, National Cancer Institute, National Institutes of Health, Department of \\ Health and Human Services, Bethesda, Maryland, USA \\ ${ }^{3}$ Urology, The University of Texas MD Anderson Cancer Center, Houston, Texas, USA \\ ${ }^{4}$ Cancer Genomics Research Laboratory, SAIC-Frederick Inc., National Cancer Institute-Frederick, Frederick, Maryland, USA \\ ${ }^{5}$ Epidemiology Research Program, American Cancer Society, Atlanta, Georgia, USA \\ ${ }^{6}$ Department of Chronic Disease Prevention, National Institute for Health and Welfare, Helsinki, Finland \\ ${ }^{7}$ Genitourinary Medical Oncology, The University of Texas MD Anderson Cancer Center, Houston, Texas, USA \\ *These authors have contributed equally to this work
}

Correspondence to:

Xifeng Wu, e-mail: xwu@mdanderson.org

Keywords: RCC, GWAS, GSEA, eQTL

Received: November 07, $2014 \quad$ Accepted: December 21, $2014 \quad$ Published: February 25, 2015

\section{ABSTRACT}

We conducted multilevel analyses to identify potential susceptibility loci for renal cell carcinoma ( $R C C)$, which may be overlooked in traditional genome-wide association studies (GWAS). A gene set enrichment analysis was performed utilizing a GWAS dataset comprised of 894 RCC cases and 1,516 controls using GenGen, SNP ratio test, and ALIGATOR. The antigen processing and presentation pathway was consistently significant $(P=0.001,=0.004$, and $<0.001$, respectively). Versatile gene-based association study approach was applied to the top-ranked pathway and identified the driven genes. By comparing the expression of the genes in RCC tumor and adjacent normal tissues, we observed significant overexpression of $H L A$ genes in tumor tissues, which was also supported by public databases. We sought to validate genetic variants in antigen processing and presentation pathway in an independent GWAS dataset comprised of 1,311 RCC cases and 3,424 control subjects from the National Cancer Institute; one SNP, rs1063355, was significant in both populations $\left(P_{\text {meta-analysis }}=9.15 \times 10^{-4}, P_{\text {heterogeneity }}=0.427\right)$. Strong correlation indicated that rs 1063355 was a cis-expression quantitative trait loci which associated with HLA$D Q B 1$ expression (Spearman's rank $r=-0.59, p=5.61 \times 10^{-6}$ ). The correlation was further validated using a public dataset. Our results highlighted the role of immunerelated pathway and genes in the etiology of RCC.

\section{INTRODUCTION}

Renal cell carcinoma (RCC) accounts for more than $80 \%$ of kidney cancers [1]. The incidence of kidney cancer has been increasing since the 1970s [2], and the disease is among the top 10 most common cancers for both males and females in the United States [2,3]. Cigarette smoking, obesity, and hypertension are well-known modifiable risk factors for RCC [2]. Other epidemiological risk factors include red meat consumption and occupational exposure to trichloroethylene [4], whereas alcohol, fruit, and vegetable consumption is suspected to be protective [2]. 
Genetic susceptibility also plays an important role in RCC risk. Individuals who have a first-degree relative with a history of kidney cancer are at more than twice the risk for developing RCC $[5,6]$. A handful of genes, such as $V H L$ and $F H$, explain a fraction of the known inherited kidney cancer syndromes [7-11]. The candidate gene approach identified several genes that could be involved in the development of sporadic RCC, such as MET, KILLIN, and FLCN [12-14]. In recent years, three susceptibility loci at the following chromosomal regions, 2p21 (EPAS1) [15], 11q13 (a CCND1 transcriptional-enhancer site) [15-17] and 2q22.3 (ZEB2) [18], have been identified for RCC by genome-wide association studies (GWAS). In addition, we previously identified a common genetic variant at $12 \mathrm{p} 11$ (ITPR2) that was associated with RCC risk [16]. The locus, which was also identified by GWAS to be associated with waist-to-hip ratio [19], may provide insight into the relationship between obesity and RCC etiology.

Although GWAS and meta-analyses conducted by large consortia have been successful in identifying SNPs associated with complex diseases, most of these SNPs are located in intergenic regions and their biological mechanisms are largely unknown. A stringent criterion for significance $\left(P<5 \times 10^{-8}\right)$ of GWAS findings in order to reduce false positive results due to multiple testing is widely accepted. In contrast, the use of gene- and pathway-based analyses of GWAS data, which takes into account the aggregated effects within a gene or pathway, substantially reduces the multiple testing burden by combining numerous genes and pathways into a reduced number of gene sets. In this study, we searched for novel potential RCC genetic susceptibility loci through analyses in pathway, gene and SNP levels, using RCC GWAS data, gene expression data, copy number variation data, public datasets and online resources.

\section{RESULTS}

Twenty one pathways were consistently significant with $p<0.05$ for all three algorithms (Table 1). In our analysis, most of the pathways identified were either immune- or cancer-related. The coverage of genes tagged by GWAS SNPs for each pathway was $80 \%$ or higher. However, only the antigen processing and presentation pathway remained significant after multiple comparison correction with a false discovery rate of 0.20 . We adjusted the top 10 principal components to control the population substructure. Results of sensitivity analysis showed the antigen processing and presentation pathway was a promising candidate (Table S1).

We further investigated the genes that drove the association for the antigen processing and presentation pathway. VEGAS results revealed that eight genes belonging to the pathway were significantly associated with RCC risk (Table 2). Four genes belong to the HLA family: $H L A-D Q A 1, H L A-D R B 1, H L A-D Q B 1$, and $H L A-F$, which were significantly overexpressed in RCC tumor tissues compared with paired adjacent normal tissues (Table 2). CREB1 and CTSL1 were slightly overexpressed but not statistically significant, while PSME3 showed a significantly reduced level in RCC tumor tissues. Among them, $H L A-D Q B 1$ had the greatest difference between paired tumor and normal tissue with a $21 \%$ increased expression in RCC tumor tissues. In addition, our findings were supported by TCGA data and 6 datasets available in Oncomine. The upregulation of HLA genes between paired tumor and normal tissue were robust in all datasets (Figure 2, Table S2 and Figure S2). No chromosomal alteration was observed for $6 \mathrm{p} 21.3$ in our Array Comparative Genomic Hybridization (array$\mathrm{CGH}$ ) data, where HLA genes are located (data not shown), and no copy number variation was observed in TCGA dataset implemented in Oncomine (data not shown). Furthermore, no somatic mutations of HLA genes were found in RCC tissue according to COSMIC database (data not shown).

We sought to validate SNPs located in our top significant pathway in an independent population. After filtering SNPs in strong linkage disequilibrium $\left(\mathrm{R}^{2}>0.8\right)$, 48 significant SNPs (all $p<0.05)$ in antigen processing and presentation pathway were sent to NCI (Table S3) for in silico validation. Only one SNP, rs1063355, was significantly associated with RCC risk in both the MD Anderson GWAS and the NCI GWAS (Table 3). The minor allele frequency of rs 10663355 in control subjects was similar in two populations. Possessing one A allele of rs 1063355 increased by $10 \%-20 \%$ the risk of RCC in both MD Anderson and NCI populations $(P=0.007$ and 0.039 , respectively). The odds ratio for the combined MD Anderson and NCI data using fixed-effect meta-analysis was $1.14\left(P=9.15 \times 10^{-4}\right.$, Cochran's Q test, $\mathrm{I}^{2}: 0.0 \%$, $\left.P_{\text {heterogeneity }}=0.427\right)$. We imputed SNPs within $+/-1 \mathrm{Mb}$ of rs1063355 (Figure S3).

The SNP rs1063355 is located in the 3'-untranslated region of $H L A-D Q B 1$. ENCyclopedia Of DNA Elements (ENCODE) data showed that rs1063355 is located within the area predicted to act as enhancers in HepG2 and GM12878 cell lines (Table S4), with four proteins (e.g. TBP, ELF1, EBF1, and TCF12) bounding to the region. The details were also visually available in the figure downloaded from the UCSC Genome Browser (Figure S4). Interestingly, the SNP was found to be in expression quantitative trait locus (eQTL) with $H L A-D Q B 1$.

To further explore the SNP-gene relationship, we performed cis-eQTL analysis for rs 1063355 in HLA-DQB1 in 51 paired RCC and adjacent normal tissues collected by our group. There were 18, 22, and 11 patients with $\mathrm{CC}$, $\mathrm{AC}$, and AA genotypes, respectively. The minor allele of rs1063355 (risk allele A) was associated with lower log2 transformed $H L A-D Q B 1$ mRNA level in adjacent normal tissues (Figure 3). Spearman's rank correlation coefficient 
Table 1: Significant ${ }^{1}$ pathways identified by GenGen, SNP ratio test, and ALIGATOR

\begin{tabular}{|c|c|c|c|c|c|}
\hline \multirow[t]{2}{*}{ Databases and pathways } & \multirow{2}{*}{$\begin{array}{l}\text { Number of genes } \\
\text { in pathway given } \\
\text { by databases }\end{array}$} & \multirow{2}{*}{$\begin{array}{l}\text { Number }(\%) \text { of } \\
\text { genes tagged by } \\
\text { study GWAS SNPs }\end{array}$} & \multicolumn{3}{|c|}{$P$ value $^{2}$} \\
\hline & & & GenGen & SNP ratio test & ALIGATOR \\
\hline \multicolumn{6}{|l|}{ KEGG } \\
\hline $\begin{array}{l}\text { Antigen processing and } \\
\text { presentation }\end{array}$ & 89 & $78(87.6 \%)$ & $0.001(0.104)$ & $0.004(0.122)$ & $\begin{array}{l}<0.001 \\
(0.028)\end{array}$ \\
\hline Asthma & 30 & $26(86.7 \%)$ & $0.019(0.423)$ & $0.027(0.167)$ & $0.043(0.986)$ \\
\hline Allograft rejection & 38 & $33(86.8 \%)$ & $0.007(0.710)$ & $0.013(0.167)$ & $0.006(0.446)$ \\
\hline Graft versus host disease & 42 & $34(81.0 \%)$ & $0.015(0.385)$ & $0.030(0.167)$ & $0.027(0.922)$ \\
\hline $\begin{array}{l}\text { Intestinal immune network for } \\
\text { IGA production }\end{array}$ & 48 & $44(91.7 \%)$ & $0.021(0.635)$ & $0.030(0.167)$ & $0.003(0.246)$ \\
\hline JAK STAT signaling & 155 & $146(94.0 \%)$ & $0.033(0.335)$ & $0.002(0.122)$ & $0.023(0.889)$ \\
\hline Leishmania infection & 72 & $63(87.5 \%)$ & $0.013(0.571)$ & $0.029(0.167)$ & $0.026(0.916)$ \\
\hline $\begin{array}{l}\text { Nod like receptor signaling } \\
\text { pathway }\end{array}$ & 62 & $58(93.5 \%)$ & $0.016(0.472)$ & $0.049(0.167)$ & $0.016(0.777)$ \\
\hline T cell receptor signaling pathway & 108 & $104(96.3 \%)$ & $0.019(0.467)$ & $0.016(0.196)$ & $0.015(0.762)$ \\
\hline \multicolumn{6}{|l|}{ BioCarta } \\
\hline Cytokine & 22 & $21(95.5 \%)$ & $0.003(0.338)$ & $<0.001(0.134)$ & $0.017(0.720)$ \\
\hline $\mathrm{DC}$ & 22 & $21(95.5 \%)$ & $\begin{array}{l}<0.001 \\
(0.151)\end{array}$ & $0.002(0.134)$ & $0.011(0.600)$ \\
\hline \multicolumn{6}{|l|}{ Reactome } \\
\hline $\begin{array}{l}\text { CREB phosphorylation through } \\
\text { the activation of RAS }\end{array}$ & 27 & $23(85.2 \%)$ & $0.039(0.850)$ & $0.006(0.408)$ & $0.005(0.509)$ \\
\hline $\begin{array}{l}\text { CREB phosphorylation through } \\
\text { the activation of CAMKII }\end{array}$ & 15 & $15(100 \%)$ & $0.047(0.781)$ & $0.011(0.523)$ & $0.006(0.600)$ \\
\hline $\begin{array}{l}\text { NEF mediates down modulation } \\
\text { of cell surface receptors by recrui- } \\
\text { ting them to clathrin adapters }\end{array}$ & 21 & $20(95.2 \%)$ & $0.049(0.810)$ & $0.026(0.586)$ & $0.015(0.877)$ \\
\hline \multicolumn{6}{|l|}{ GO } \\
\hline Microtubule cytoskeleton & 152 & $138(90.8 \%)$ & $0.007(0.462)$ & $0.048(0.528)$ & $0.013(0.995)$ \\
\hline $\begin{array}{l}\text { Hematopoietin interferon } \\
\text { classd } 200 \text { domain cytokine } \\
\text { receptor binding }\end{array}$ & 29 & $29(100 \%)$ & $0.007(0.712)$ & $0.020(0.528)$ & $0.013(0.995)$ \\
\hline Cytokine activity & 113 & $108(95.6 \%)$ & $0.010(0.413)$ & $0.013(0.528)$ & $0.015(0.998)$ \\
\hline Response to temperature stimulus & 16 & $15(93.8 \%)$ & $0.025(0.813)$ & $0.048(0.528)$ & $0.007(0.961)$ \\
\hline $\begin{array}{l}\text { Negative regulation of } \\
\text { transferase activity }\end{array}$ & 35 & $34(97.1 \%)$ & $0.025(0.720)$ & $0.007(0.528)$ & $0.022(1.000)$ \\
\hline Kinase regulator activity & 46 & $43(93.5 \%)$ & $0.030(0.690)$ & $0.016(0.528)$ & $0.014(0.998)$ \\
\hline $\begin{array}{l}\text { Positive regulation of } t \text { cell } \\
\text { proliferation }\end{array}$ & 13 & $12(92.3 \%)$ & $0.037(0.934)$ & $0.031(0.528)$ & $0.019(1.000)$ \\
\hline
\end{tabular}

1. Significance was determined based on $p<0.05$ calculated by all three tests.

2. Values in parentheses are FDR corrected. 
Table 2: VEGAS gene-based test results of the antigen processing and presentation pathway and gene expression comparison between paired $\mathrm{RCC}$ and adjacent normal tissues

\begin{tabular}{|c|c|c|c|c|c|c|c|}
\hline \multirow[b]{2}{*}{ Gene } & \multirow[b]{2}{*}{ Chromosome } & \multirow[b]{2}{*}{$\begin{array}{c}\text { No. of SNPs } \\
\text { mapped to gene }\end{array}$} & \multirow[b]{2}{*}{$P_{\text {VEGaS }}{ }^{1}$} & \multicolumn{4}{|c|}{ Gene expression level ${ }^{2}($ mean \pm SD) } \\
\hline & & & & $\begin{array}{l}\text { Normal } \\
\text { tissue }\end{array}$ & RCCtissue & $\begin{array}{c}\text { Fold } \\
\text { change }^{3}\end{array}$ & $P$ value $^{4}$ \\
\hline HLA-DQA1 & 6 & 11 & $0.0039(0.094)$ & $9.30(1.31)$ & 10.91(1.48) & 1.17 & 3.92E-08 \\
\hline CTSL1 & 9 & 16 & $0.0048(0.094)$ & $10.09(0.79)$ & $10.40(1.11)$ & 1.03 & 0.076 \\
\hline HLA-DRB1 & 6 & 8 & $0.0051(0.094)$ & $8.24(2.10)$ & $9.04(2.55)$ & 1.10 & $5.61 \mathrm{E}-04$ \\
\hline HLA-DQB1 & 6 & 7 & $0.0082(0.113)$ & $7.20(1.17)$ & $8.69(1.72)$ & 1.21 & $5.00 \mathrm{E}-09$ \\
\hline PDIA3 & 15 & 2 & $0.0120(0.133)$ & N.A. & N.A. & N.A. & N.A. \\
\hline PSME3 & 17 & 1 & $0.0181(0.167)$ & $8.60(0.70)$ & $8.16(0.70)$ & 0.95 & $2.59 \mathrm{E}-06$ \\
\hline HLA-F & 6 & 25 & $0.0378(0.299)$ & $8.18(0.97)$ & $9.68(1.15)$ & 1.18 & 2.67E-11 \\
\hline CREB1 & 2 & 9 & $0.0436(0.299)$ & $7.00(0.53)$ & $7.14(0.59)$ & 1.02 & 0.103 \\
\hline
\end{tabular}

HLA-DQA1: major histocompatibility complex, class II, DQ alpha 1.

CTSL1: cathepsin L1.

HLA-DRB 1: major histocompatibility complex, class II, DR beta 1.

$H L A-D Q B 1$ : major histocompatibility complex, class II, DQ beta 1.

PDIA3: protein disulfide isomerase family A, member 3.

PSME3: proteasome activator subunit 3.

$H L A-F$ : major histocompatibility complex, class I, F.

CREB 1: cAMP responsive element binding protein 1.

${ }^{1} \mathrm{P}_{\text {VEGAS }}$ was obtained using VEGAS, corresponding $q$ value was listed in the parenthesis.

${ }^{2}$ Expression data were quantile normalized and $\log 2$ transformed.

${ }^{3}$ Fold change $=\mathrm{RCC} /$ Normal, based on mean of $\log 2$ transformed data.

${ }^{4} P$ value was calculated by paired Student's $t$-test.

N.A.: Data not available.

Table 3: Validation of SNPs in antigen process and presentation pathway

\begin{tabular}{l|c|c|c|c|c|c|c|}
\hline \multicolumn{1}{l}{ SNP } & \multicolumn{1}{c}{ Nearby Gene } & \multicolumn{1}{c}{ Minor } & \multicolumn{1}{c}{ MAF } & \multicolumn{1}{c}{ OR (95\%CI) } & \multicolumn{1}{c}{$\boldsymbol{P}_{\text {value }}$} & Higgins' I $^{2}$ & $\boldsymbol{P}_{\text {heterogeneity }}$ \\
\hline rs1063355 & HLA-DQB1 & & & & & & \\
\hline MDA & & A & $0.44 / 0.40$ & $1.19(1.05-1.34)$ & 0.007 & & \\
\hline NCI & & A & $0.44 / 0.43$ & $1.11(1.01-1.23)$ & 0.039 & & \\
\hline Overall & & & & $1.14(1.06-1.23)$ & $9.15 \mathrm{E}-4^{\&}$ & $0.0 \%$ & 0.427 \\
\hline
\end{tabular}

$\S$ MAF: minor allele frequency in cases/control.

" Adjusted for age (5-year intervals), and sex under additive model.

\& Meta $p$-value is calculated assuming fixed effect model.

was $-0.59\left(p=5.61 \times 10^{-6}\right)$. Result of linear model showed possessing one copy of risk allele of rs 1063355 could reduce 0.80 unit of $\log 2$ transformed $H L A-D Q B 1$ mRNA level ( $p<0.001$, data not shown). The same trend was observed in RCC tumor tissue (data not shown). We further evaluated the correlation for all SNPs in 3'UTR of $H L A-D Q B 1$ where rs 1063355 is located. Rs1063355 was in high LD with the imputed SNP which possessed the top significant GWAS and eQTL association (e.g. rs1063345, $\left.\mathrm{R}^{2}=0.99\right)$ in both tumor and normal tissues (Table S5). To corroborate these findings, we used public MuTHER dataset for replication. It supported our findings that
$H L A-D Q B 1$ was under-expressed in lymphoblastoid cell lines, adipose tissues, and skin tissues of subjects with the AA genotype of rs1063355 compared to subjects with the $\mathrm{AC}$ or $\mathrm{CC}$ genotype. The correlations remained significant in permutation test for three types of tissue (Figure 4).

\section{DISCUSSION}

To our knowledge, this is the first study to use multilevel approaches including discovery analysis of GWAS, gene expression correlation analyses, and 


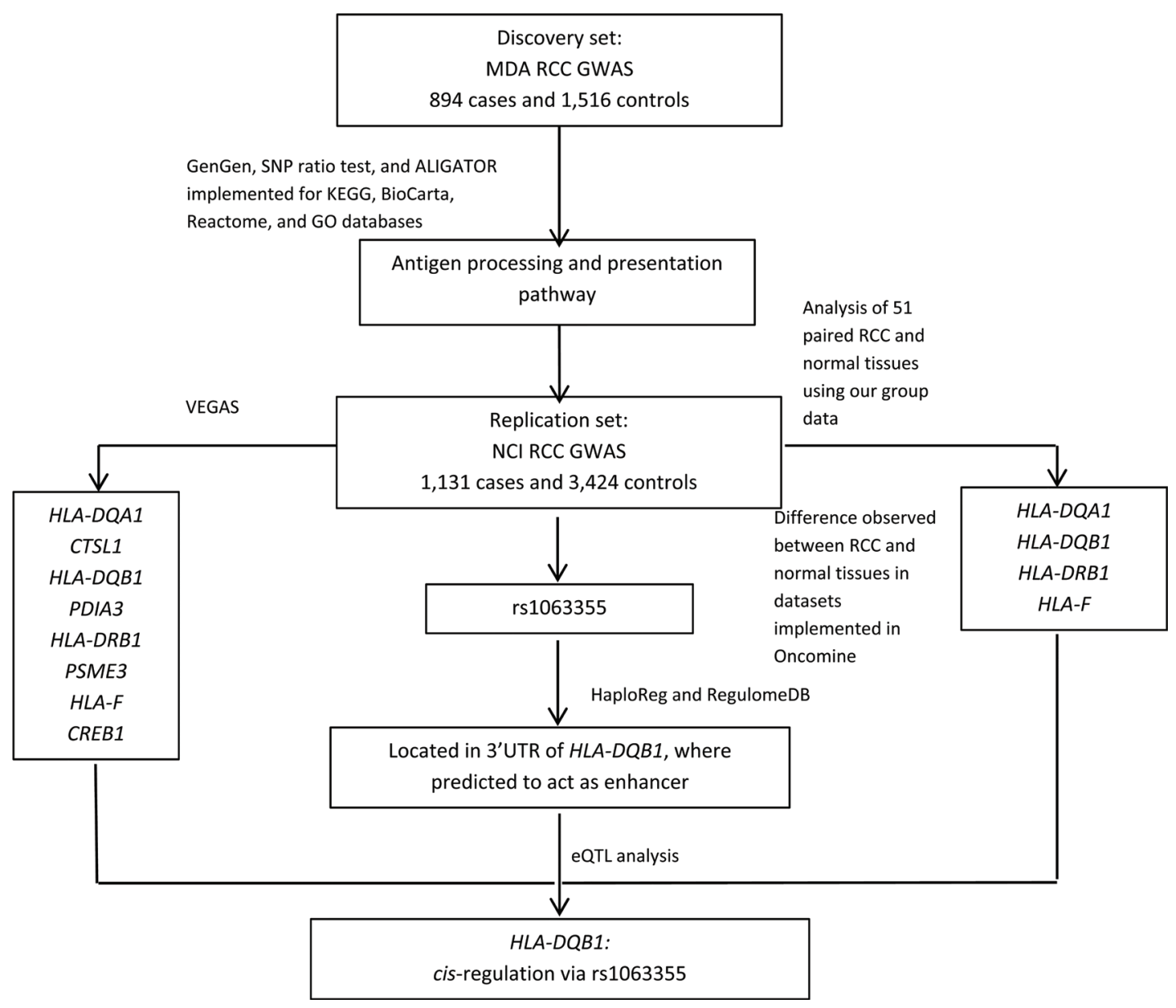

Figure 1: Study flowchart.

online resources to investigate the aggregated effect of common SNPs in relation to RCC etiology with respect to defined pathways and genes. To assure reliability, three analytical algorithms and four commonly used pathway collection databases were applied in pathway analysis with correction for multiple comparisons. Our identification of the antigen processing and presentation pathway and $H L A$ genes supports an important role for the immune system in RCC etiology. The validation on SNP level and eQTL analysis identified a new potential susceptibility region and a putative functional SNP which could help to elucidate the biological mechanisms underlying RCC development.

The results of VEGAS and the gene expression level comparison between RCC tumor and adjacent normal tissues indicated that major histocompatibility complex (MHC) loci, in particular $H L A-D Q B 1$, may contribute to RCC etiology. HLA-DQBI belongs to HLA class II beta chain paralogs which, along with an alpha chain, forms the HLA class II heterodimer. The HLA-DQ protein is usually expressed on the surface of antigen presenting cells and plays a critical role in preparing and presenting peptides to $\mathrm{T}$ cells. The difference in gene expression levels could be related to local copy number variation. However, we did not find any alteration in the region in either our own data or in TCGA data, indicating that the expression may be affected through other mechanisms. Considering the location of rs1063355, we hypothesized that this SNP or linked SNPs were associated with the expression level of $H L A-D Q B 1$.

Interestingly, the contrasting results of associations between rs1063355, HLA-DQB1 expression, and RCC risk suggested a complex relationship. Since the risk variant (allele A) of rs1063355 were associated with reduced $H L A-D Q B 1$ expression, our results suggested that underexpression of $H L A-D Q B 1$ may increase the RCC risk. In contrast, overexpression of $H L A-D Q B 1$ found in RCC tissue revealed the complexity of abnormal alterations in tumor tissue. The inflammation that occurs during cancer development may actually induce MHC expression in tissues or tumor cells [20,21], which may support the observation of higher expression level of $H L A-D Q B 1$ in RCC tissues. Thus, we hypothesized that reduced $H L A-D Q B 1$ expression may play a crucial role to avoid immune surveillance during tumorigenesis, but overexpression may be an adaptive response once the transformation is complete. Future functional assays are needed to elucidate this sophisticated framework. 


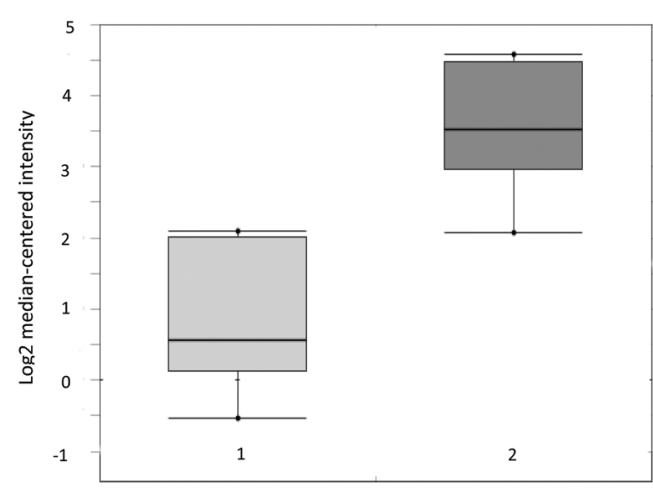

A. Lenburg. 1: Kidney; 2: RCC

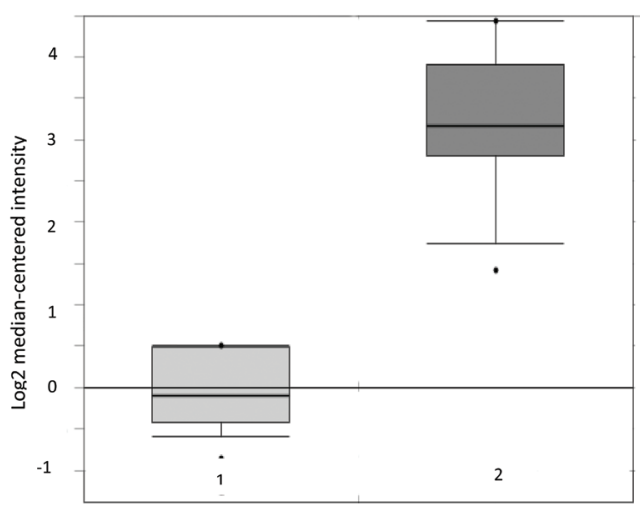

C. Gumz. 1: Kidney; 2: RCC

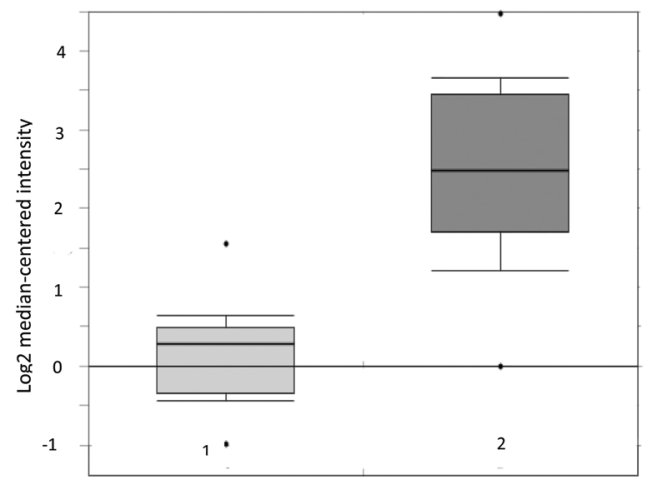

E. Jones. 1: Kidnev; 2: RCC

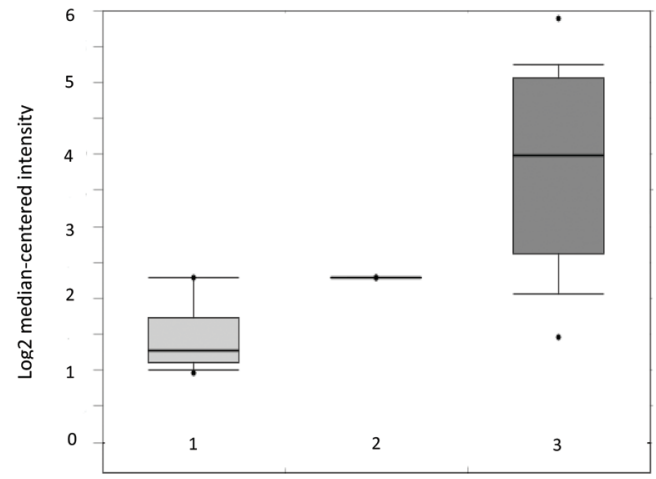

B. Beroukhim. 1: Renal Cortex, 2: Renal Tissue; 3: Non-Hereditary RCC

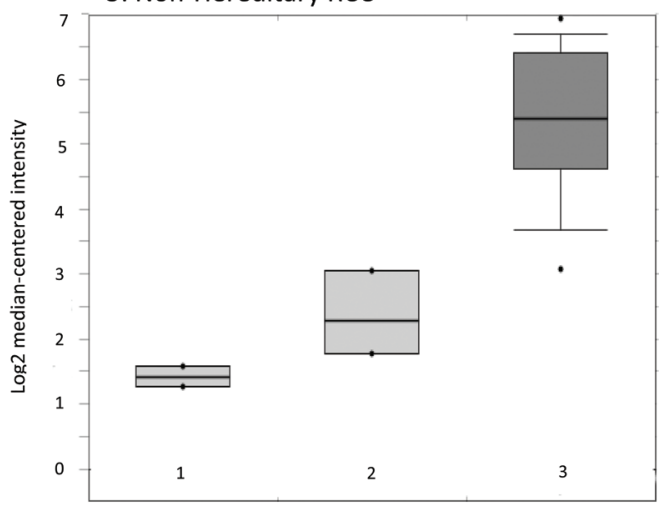

D. Yusenko. 1: Fetal kidney; 2: Kidney; 3: RCC

Figure 2: Boxplot of $H L A-D Q B 1 \mathrm{mRNA}$ levels in RCC and adjacent normal tissue as reported in five datasets available in the Oncomine database. The probe selected for all datasets $\left(212998 \_\times \_\right.$at) was defined in Oncomine. (The sixth study was not included here because its platform was not pre-defined in Oncomine, although the change in the same direction was detected.) A, Lenburg. B, Beroukhim. C, Gumz. D, Yusenko. E, Jones. Circles stand for outliers. The figures were directly downloaded from Oncomine.

Regions on or close to $H L A-D Q B 1$ (6p21.3) were frequently identified by GWAS as susceptibility loci for many complex diseases, such as lymphoma [22], type 1 diabetes [23], asthma [24], systemic sclerosis [25], and narcolepsy [26]. The intergenic region between $H L A$ $D Q B 1$ and $H L A-D Q B 2$ was linked to IgA nephropathy in one GWAS study [27]; but to date no epidemiologic study has linked IgA nephropathy to kidney malignancy. In addition, one study has reported that multi-loci haplotypes were associated with a risk for cervical cancer [28]. The region was also found to be associated with hepatitis $B$ virus-related hepatocellular carcinoma risk in Chinese population [29].

The present study has numerous strengths, including large sample sizes for the discovery and replication populations. Additionally, we were able to validate the finding at the SNP and gene expression level. We were also able to validate the eQTL analyses by using a publicly 


\section{A. Adjacent Normal}

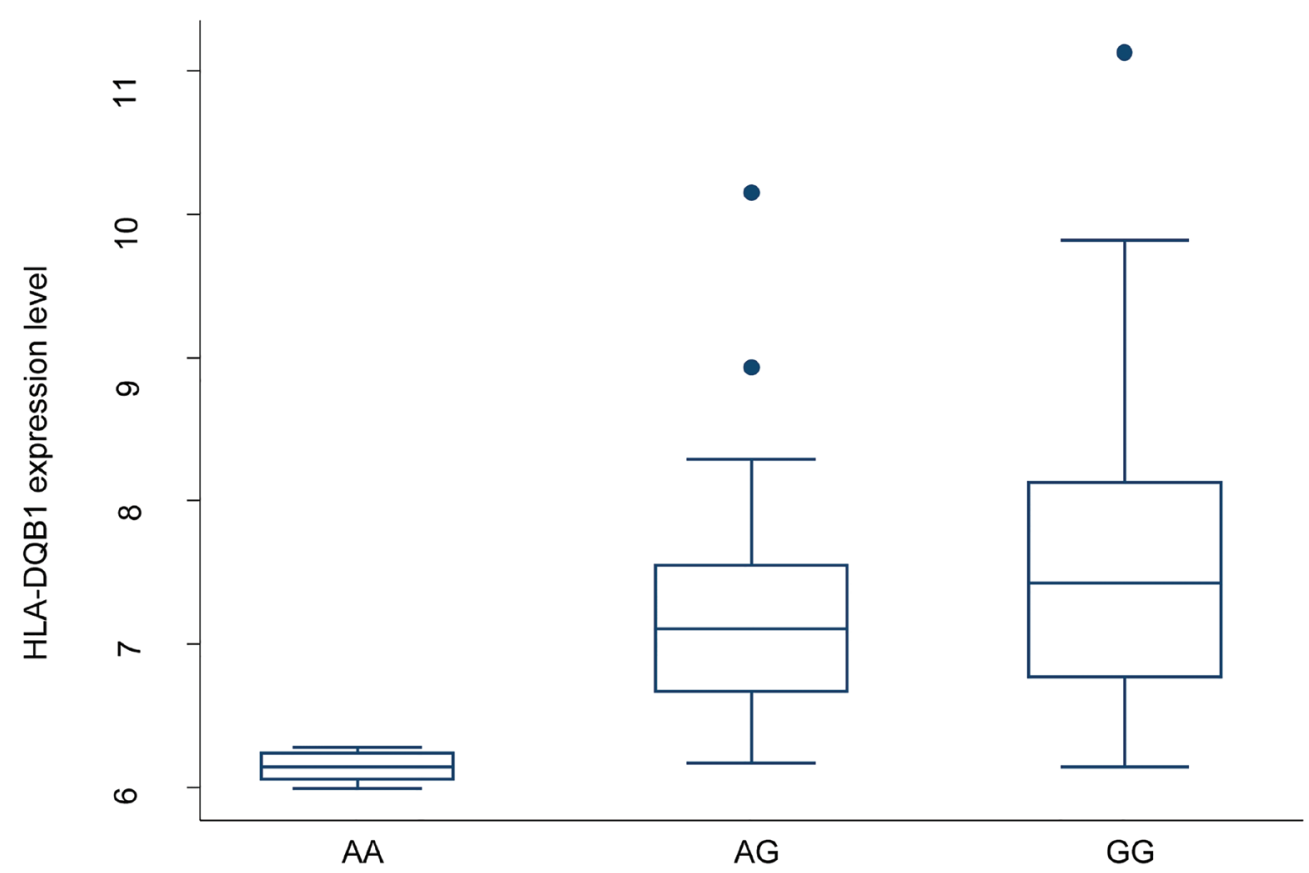

B. RCC tumor

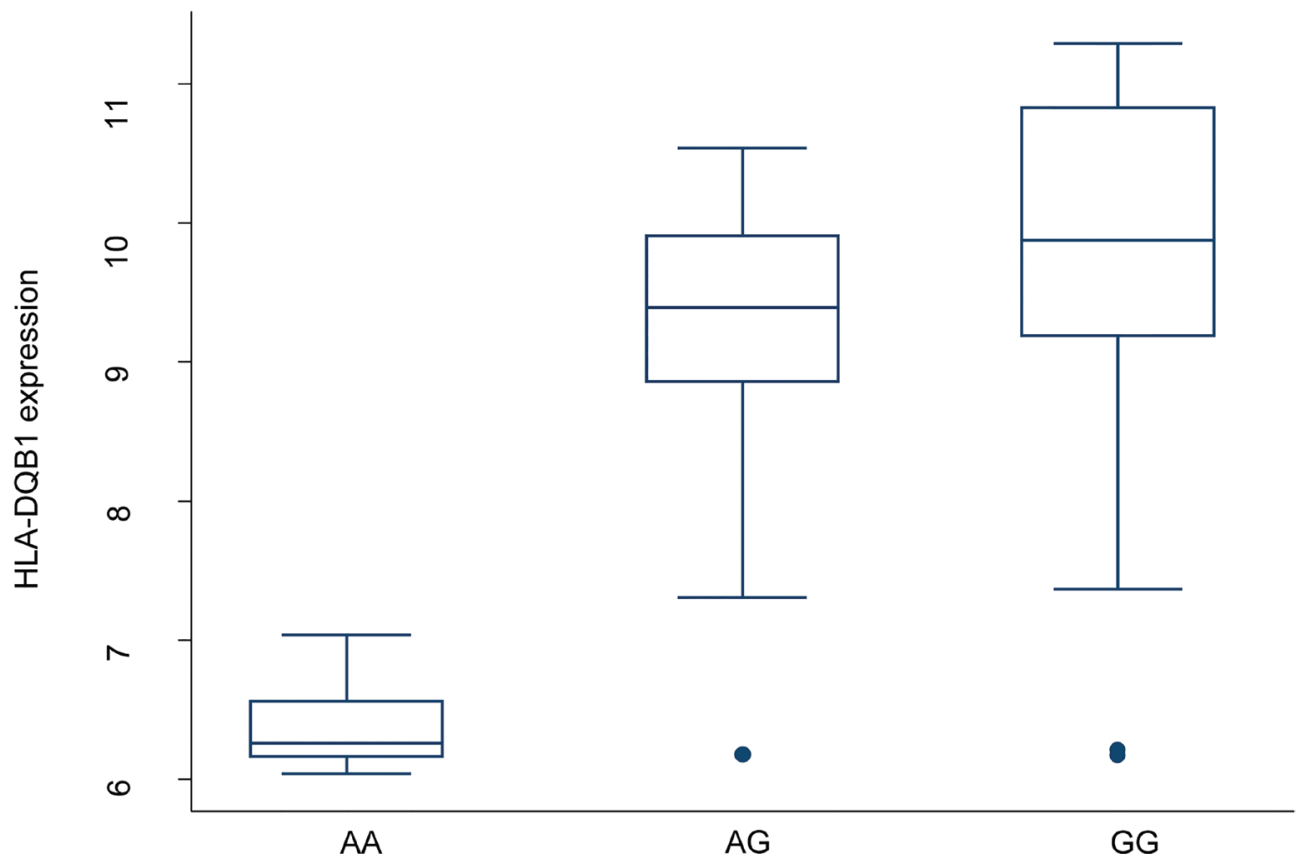

Figure 3: Boxplot of $H L A-D Q B 1$ mRNA level categorized by rs1063355 genotype. Both genotyping and gene expression data were available 51 pairs of RCC and adjacent normal tissues collected at MD Anderson. The genotype was CC for 18 study subjects, AC for 22 , and AA for 11. Spearman's $r=-0.59, \mathrm{P}_{\text {trend }}=5.61 \mathrm{E}-6$ in normal tissue. The same trend was observed in tumor tissue. The coefficient obtained from simple linear regression was $-0.80(95 \% \mathrm{CI}=-1.18$ to $-0.41, p<0.001)$. The expression level of $H L A-D Q B 1$ was $\log 2$ transformed. Circles stand for outliers. 
Twin1-A

$R h o=0.696 \mathrm{P}=1.1 \mathrm{E}-12$ Pemp $<1.0 \mathrm{E}-04$

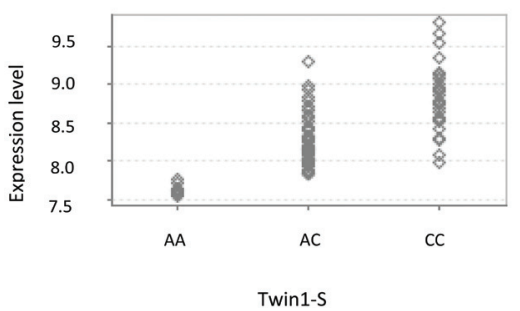

Rho $=0.581 \mathrm{P}=3.7 \mathrm{E}-8$ Pemp<1.0E- 04

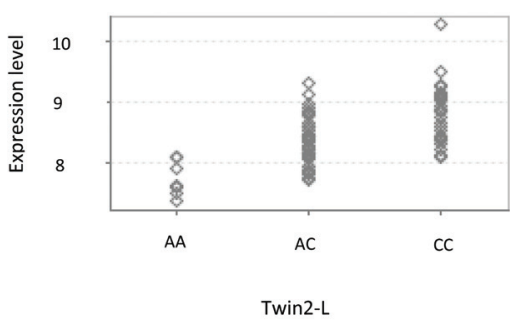

Rho $=0.749 P=6.3 E-16$ Pemp $<1.0 E-04$

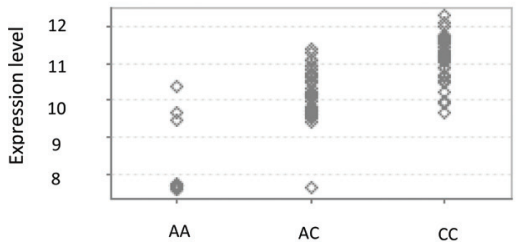

Twin1-L

Rho=0.677 $P=3.4 E-11$ Pemp $<1.0 E-04$

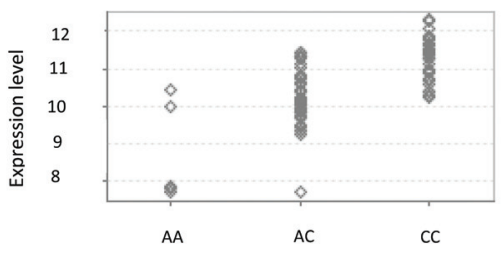

Twin2-A

Rho $=0.75 \mathrm{P}=6.6 \mathrm{E}-17 \mathrm{Pemp}<1.0 \mathrm{E}-04$

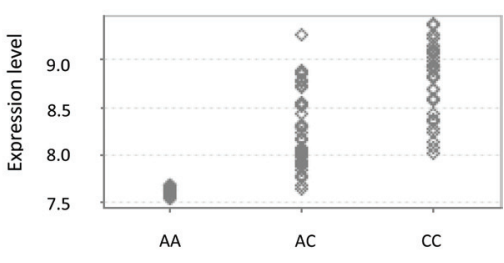

Twin2-S

Rho $=0.568 \mathrm{P}=1.8 \mathrm{E}-8$ Pemp $<1.0 \mathrm{E}-04$

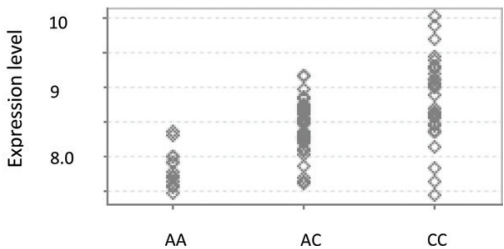

Figure 4: eQTL analysis for rs1063355 and $H L A-D Q B 1$ in a public dataset. The MuTHER pilot study collected adipose tissue (A), lymphoblastoid cell lines (L), and skin tissue (S) from healthy Caucasian female twins. All figures were directly downloaded from Genevar. Rho: Spearman's correlation coefficient. P: Corresponding $p$ value. Pemp: Empirical $p$ values calculated from 10,000 permutations.

available dataset. Importantly, the SNPs we identified may regulate $H L A-D Q B 1$ transcription level in cis. However, limitations of this study warrant consideration. Specifically, the biological mechanism that describes how this SNP affects $H L A-D Q B 1$ expression was not investigated and remains unknown. It is possible that other linked functional SNPs, rather than rs1063355, contribute to the difference in $H L A-D Q B 1$ expression level observed in individuals with distinct genotypes. In addition, the identified pathway and genes showed modest significance when multiple testing is considered, and only one SNP in antigen processing and presentation pathway was significant in NCI samples with moderate $p$ value. Nevertheless, there is biological plausibility for the association of $H L A-D Q B 1$ and cancer risk. The evidence that rs1063355 or other SNPs in linkage disequilibrium could be potentially functional and driving the association, is promising. Thus, the locus remains interesting to be further investigated.

In conclusion, the results of multilevel analyses in this study support the idea that the HLA class II region may influence RCC tumorigenesis. Moreover, we found a variant in $H L A-D Q B 1$, replicated in an independent population, could alter cancer risk in a cis-eQTL manner. However, overexpression of $H L A-D Q B 1$ in RCC tissue revealed the complexity of the biological mechanisms underlying the process of tumor formation. Further studies are required to validate our findings. Functional assays are needed to elucidate the biological mechanism involved in the regulation of $H L A-D Q B 1$ expression and the SNP's role in RCC etiology.

\section{MATERIALS AND METHODS}

Figure 1 illustrates the steps used in this study to identify potential susceptibility loci for RCC.

\section{Study population}

The details of the study population for the RCC GWAS conducted previously have been described elsewhere [16]. Briefly, newly diagnosed and histologically confirmed RCC cases and healthy control subjects were recruited from an ongoing $\mathrm{RCC}$ case-control study that began in 2002 at The University of Texas MD Anderson Cancer Center in Houston, TX. The recruitment of control subjects in Texas was performed via random digital dialing [30]. An additional set of control subjects from an ongoing bladder cancer case-control study, who were involved in a previously published GWAS of bladder cancer, was also included [31]. Recruitment was not restricted by age, sex, ethnicity, or cancer stage. A control subject had to have lived for no less than 1 year in the same county or 
socio-economically matched surrounding counties where a case subject resided. Healthy controls were individuals who had no history of cancer (except non-melanoma skin cancer) at the time of recruitment. Cases and controls were frequency matched by age ( \pm 5 years), sex, and county of residence. However, only cases and controls who selfreported to have European ancestry were included in the analysis of our RCC GWAS study. Informed consent had been obtained from all study participants before epidemiological data and blood samples were collected by trained MD Anderson staff interviewers. The study was approved by the Institutional Review Board at the MD Anderson Cancer Center, and informed consent was obtained from all participants for discovery set.

\section{Validation population}

We used the U.S. National Cancer Institute (NCI) RCC GWAS to validate statistically significant SNPs $(p<0.05)$ identified from the MD Anderson GWAS. The NCI participants had been recruited from 4 studies [Prostate, Lung, Colorectal and Ovarian Cancer Screening Trial (PLCO), American Cancer Society Cancer Prevention Study II Nutrition Cohort (CPS-II), Alpha-Tocopherol, Beta-Carotene Cancer Prevention Study (ATBC), and National Cancer Institute United States Kidney Cancer Study (USKC)] and informed consent had been collected from each participant. After the quality control procedures were completed, the study comprised of 1,311 cases and 3,424 controls. The details of the study design and population characteristics were previously described [15]. Informed consent was obtained from all participants, and each study was approved by the appropriate institutional review boards and/or ethics committees for replication set.

\section{Genotyping}

Information on the platforms used for the primary scan of our population and the quality controls were described previously [16]. In short, the primary scan for the discovery population was performed at MD Anderson using HumanHap610/660W BeadChips (Illumina, San Diego, CA, USA) [16, 31]. After quality control procedures were completed, 2,410 samples, including 894 RCC cases and 1,516 healthy controls were available for analysis. A total of 533,191 SNPs were included in the final analysis. There was no evidence of differences in population substructure (inflation factor $\lambda=1.037$ ). HumanHap 500, 610, or $660 \mathrm{~W}$ BeadChips were used in the primary scan of the NCI population; details can be found in a previous publication [15].

\section{Gene expression, eQTL analysis, copy number variation, and mutation spectrum in tissues}

Gene expression assays were performed in 51 pairs of RCC tumor tissue and adjacent normal tissue collected from patients who had been recruited to our RCC case-control study. Total RNA was isolated using the mirVana RNA isolation kit (Ambion, Austin, TX) according to the standard protocol from approximately 20 $\mathrm{mg}$ of flash-frozen tissue, which was placed in RNAlaterICE frozen tissue transition solution (Ambion) at $-20^{\circ} \mathrm{C}$. HumanHT-12 v2 Expression BeadChip kits (Illumina) was used to profile the whole genome-wide gene expression and were read using a BeadStation 500 scanner (Illumina). Arrays were quantile normalized and the data were log2 transformed. To corroborate our results, we also checked genes from top significant pathway in Oncomine. Six studies were available for the analysis in Oncomine [32-37]. For robustness of each gene, we compared the number of studies with significantly altered expression level, average $p$-value, and median rank (sort by $p$-value) among genes across all datasets in Oncomine. We also used USCS Cancer Browser to explore the gene expression level for our genes in the TCGA database.

We conducted expression quantitative trait loci (eQTL) analysis for our candidate SNP using mRNA microarray data generated from paired RCC tumor and adjacent normal tissues. To show rs1063355 was the best GWAS and eQTL SNP in the region, we also assessed the correlation for all imputed and genotyped SNPs physically close to it (chromosomal region of $3^{\prime} \mathrm{UTR}$ of $H L A-D Q B 1$ ). The public resource Genevar [38] contains 4 eQTL studies which could be used for the replication set. However, only the MuTHER pilot study [39] has both rs1063355 genotyping and $H L A-D Q B 1$ expression data available for the analysis. Three types of tissues were collected including lymphoblastoid cell lines, adiposity tissues, and skin tissues in the MuTHER pilot study. We checked the Spearman's correlation of SNP-gene within a $1 \mathrm{Mb}$ region where the SNPs is located for all three types of tissue.

We checked the copy number variation in the region identified using the data produced by our group using a method described previously [40]. TCGA Renal 2 data implemented in Oncomine was also used for assessing the gene copy number variation. It compared copy number of genes among 489 clear cell renal cell carcinoma, 43 papillary renal cell carcinoma, 441 paired normal kidney tissue samples and 98 paired normal blood specimen.

Information on the somatic mutations of significant genes identified in our analyses can be found in the Catalogue of Somatic Mutations in Cancer (COSMIC).

\section{SNP function annotations}

To predict the putative function of rs1063355, we used HaploReg [41] and RegulomeDB [42] to analyze the ENCODE data [43].

\section{Statistical analysis}

We applied three gene set enrichment analysis (GSEA) tools to four well-characterized pathway 
databases. Gene-based tests were performed for the most promising pathway we identified. Gene expression levels were compared between paired RCC and adjacent normal tissue. We sought validation from SNP level in an independent NCI RCC GWAS.

Pathway Databases. Four frequently used pathway databases (KEGG, BioCarta, Reactome, and GO) were downloaded from the Molecular Signatures Database by selecting "C2: Curated gene sets" (for KEGG, BioCarta, and Reactome) or "C5: GO gene sets" (for GO). Three types of datasets were available from the Molecular Signatures Database; we used the file contained "Entrez Gene IDs". This dataset contained 186, 217, 430 and 1454 gene sets in KEGG, BioCarta, Reactome, and GO, respectively.

Gene Annotation. We used the gene annotation file "NCBI Build 36" from the National Center for Biotechnology Information website. This file provided gene location information.

SNP Mapping to Genes. We used the University of California, Santa Cruz Genome Browser to retrieve the locus information for each SNP of interest by selecting "NCBI 36/hg 18" and "SNP 129". A total of 533,126 SNPs was matched with the database and their positions in a specific chromosome were successfully obtained. We restricted our analysis to autosomal chromosomes, such that 12,440 SNPs in chromosome $\mathrm{X}$ and 17 SNPs in chromosome $\mathrm{Y}$ were removed from the analysis. Thus, 520,669 SNPs remained to be mapped to specific genes. SNPs within $20 \mathrm{~kb}$ upstream or downstream of a gene were considered to belong to that gene; some SNPs were mapped to more than one gene because of overlapping sequences. Due to the design of the array, not all the genes located in a pathway were captured by our GWAS data.

GSEA Tools. GenGen [44]. The methodology of GenGen has been described previously. The concept was inspired by GSEA for microarray data. In this approach, an enrichment score is calculated. One thousand permutations are performed, and the permutation-based (1,000-time) false discovery rate is calculated to assess the issue of multiple comparisons.

SNP Ratio Test [45]. This test calculates the proportion of significant SNPs in a specified pathway. The empirical $p$-value is calculated based on 1,000 permutations. We also calculated the false discovery rate for empirical $p$-values.

ALIGATOR [46]. This approach counts the number of significant genes represented by significant SNPs. Each significant gene is counted only once regardless of how many significant SNPs map to that gene. A bootstrap approach (repeated 1,000 times) is applied to correct the empirical $p$-values.

In addition, we adjusted the size of the pathway by confining the number of genes to between 10 and 200 . Finally, 180, 206, 402 and 1,226 pathways were included in the analysis for the KEGG, BioCarta, Reactome, and GO databases, respectively. A pathway was considered significant if the $p$-value was $<0.05$ for all three GSEA algorithms. We further adjusted for top 10 principal components (Figure S1) in the model and performed the same analyses. Principal component analysis was conducted using EIGENSTRAT [47].

Versatile Gene-Based Association Study (VEGAS). For the gene-based test, we used VEGAS [48] to investigate aggregated signals within specific genes located in the most promising pathway. SNP level $p$-values were used as input into the program to produce an empirical gene-based $p$-value by simulation.

Validation of SNPs in a Pathway. We extracted all SNPs mapped to the most promising pathway. Multivariable logistic regression adjusted for age (in 5 -year intervals) and sex were conducted for each SNP in an additive model. We sought to replicate only significant SNPs $(p<0.05)$. From a subset of SNPs located in the same linkage disequilibrium block $\left(\mathrm{R}^{2}>0.8\right)$, the SNP with the smallest $p$ value was selected to represent the block. Finally, 48 SNPs were selected for validation with the NCI RCC GWAS population. Results of two studies were pooled by meta-analysis. Selection of a fixedeffect model depended on the results of Cochran's Q test for heterogeneity being $P_{\text {heterogeneity }} \geq 0.05$; otherwise, a random-effect model would be adopted. The per-allele trend effect was estimated and the $P$ value was computed using inverse variance weighting.

Other Statistical Analyses. For data generated from samples collected by our group, paired $t$ test was used to compare gene expression between paired RCC and adjacent normal tissues. Spearman's rank correlation, linear model and corresponding $p$-values were calculated for SNPs and genes of interest. Imputation of the $+/-1 \mathrm{Mb}$ region of where a SNP was located was conducted with IMPUTE2 [49, 50]. After quality control, 10,909 SNPs (Imputation Score $\geq 0.5, \mathrm{MAF}>0.01, \mathrm{HWE} p$-value $<0.001$, genotype call rate $>0.90$ ) were found in $a \pm 1 \mathrm{Mb}$ region up/downstream of where rs1063355 is located. All statistical analyses were done using Stata 10.0 (College Station, TX, USA). All correlation association analyses were conducted with respect to the minor allele.

\section{Web resources}

Oncomine: https://www.oncomine.org

USCS Cancer Browser: https://genome-cancer.ucsc. edu/proj/site/hgHeatmap/

Genome Browser: http://genome.ucsc.edu/

COSMIC: http://cancer.sanger.ac.uk/cancergenome/ projects/cosmic/

Molecular Signatures Database: http://www. broadinstitute.org/gsea/msigdb/index.jsp

NCBI: http:/www.ncbi.nlm.nih.gov/ VEGAS: http://gump.qimr.edu.au/VEGAS/

IMPUTE2: http://mathgen.stats.ox.ac.uk/impute/ impute_v2.html\#home 


\section{ACKNOWLEDGEMENTS}

This work was supported in part by grants from the National Institutes of Health (R01 CA170298); and by the University of Texas MD Anderson Cancer Center, Duncan Family Institute for Cancer Prevention institutional support for the Center for Translational and Public Health Genomics.

\section{Abbreviations}

SNP: single nucleotide polymorphism.

GWAS: genome-wide association study.

RCC: renal cell carcinoma.

GSEA: gene set enrichment analysis.

VEGAS: Versatile Gene-Based Association Study. eQTL: Expression Quantitative Trait Locus.

\section{REFERENCES}

1. Chow WH, Devesa SS, Warren JL, Fraumeni JF Jr. Rising incidence of renal cell cancer in the United States. JAMA. 1999; 281:1628-1631.

2. Chow WH, Dong LM, Devesa SS. Epidemiology and risk factors for kidney cancer. Nat Rev Urol. 2010; 7:245-257.

3. Siegel R, Naishadham D, Jemal A. Cancer statistics. CA Cancer J Clin. 2012; 62:10-29.

4. Guha N, Loomis D, Grosse Y, Lauby-Secretan B, El Ghissassi F, Bouvard V, Benbrahim-Tallaa L, Baan R, Mattock H, Straif K. Carcinogenicity of trichloroethylene, tetrachloroethylene, some other chlorinated solvents, and their metabolites. Lancet Oncol. 2012; 13:1192-1193.

5. Clague J, Lin J, Cassidy A, Matin S, Tannir NM, Tamboli P, Wood CG, Wu X. Family history and risk of renal cell carcinoma: results from a case-control study and systematic meta-analysis. Cancer Epidemiol Biomarkers Prev. 2009; 18:801-807.

6. Gago-Dominguez M, Yuan JM, Castelao JE, Ross RK, $\mathrm{Yu}$ MC. Family history and risk of renal cell carcinoma. Cancer Epidemiol Biomarkers Prev. 2001; 10:1001-1004.

7. Latif F, Tory K, Gnarra J, Yao M, Duh FM, Orcutt ML, Stackhouse T, Kuzmin I, Modi W, Geil L, et al. Identification of the von Hippel-Lindau disease tumor suppressor gene. Science. 1993; 260:1317-1320.

8. Schmidt L, Duh FM, Chen F, Kishida T, Glenn G, Choyke P, Scherer SW, Zhuang Z, Lubensky I, Dean M, Allikmets R, Chidambaram A, Bergerheim UR, Feltis JT, Casadevall C, Zamarron A, et al. Germline and somatic mutations in the tyrosine kinase domain of the MET proto-oncogene in papillary renal carcinomas. Nat Genet. 1997; 16:68-73.

9. Tomlinson IP, Alam NA, Rowan AJ, Barclay E, Jaeger EE, Kelsell D, Leigh I, Gorman P, Lamlum H, Rahman S, Roylance RR, Olpin S, Bevan S, Barker K, Hearle N, Houlston RS, et al. Germline mutations in FH predispose to dominantly inherited uterine fibroids, skin leiomyomata and papillary renal cell cancer. Nat Genet. 2002; 30:406-410.
10. Linehan WM, Srinivasan R, Schmidt LS. The genetic basis of kidney cancer: a metabolic disease. Nat Rev Urol. 2010; $7: 277-285$

11. Linehan WM, Lerman MI, Zbar B. Identification of the von Hippel-Lindau (VHL) gene. Its role in renal cancer. JAMA. 1995; 273:564-570.

12. Peruzzi B, Bottaro DP. Targeting the c-Met signaling pathway in cancer. Clin Cancer Res. 2006; 12:3657-3660.

13. Bennett KL, Mester J, Eng C. Germline epigenetic regulation of KILLIN in Cowden and Cowden-like syndrome. JAMA. 2010; 304:2724-2731.

14. Schmidt LS, Warren MB, Nickerson ML, Weirich G, Matrosova V, Toro JR, Turner ML, Duray P, Merino M, Hewitt S, Pavlovich CP, Glenn G, Greenberg CR, Linehan WM, Zbar B. Birt-Hogg-Dube syndrome, a genodermatosis associated with spontaneous pneumothorax and kidney neoplasia, maps to chromosome 17p11.2. Am J Hum Genet. 2001; 69:876-882.

15. Purdue MP, Johansson M, Zelenika D, Toro JR, Scelo G, Moore LE, Prokhortchouk E, Wu X, Kiemeney LA, Gaborieau V, Jacobs KB, Chow WH, Zaridze D, Matveev V, Lubinski J, Trubicka J, et al. Genome-wide association study of renal cell carcinoma identifies two susceptibility loci on 2p21 and 11q13.3. Nat Genet. 2011; 43:60-65.

16. Wu X, Scelo G, Purdue MP, Rothman N, Johansson M, Ye Y, Wang Z, Zelenika D, Moore LE, Wood CG, Prokhortchouk E, Gaborieau V, Jacobs KB, Chow WH, Toro JR, Zaridze D, et al. A genome-wide association study identifies a novel susceptibility locus for renal cell carcinoma on 12p11.23. Hum Mol Genet. 2012; 21:456-462.

17. Schodel J, Bardella C, Sciesielski LK, Brown JM, Pugh CW, Buckle V, Tomlinson IP, Ratcliffe PJ, Mole DR. Common genetic variants at the $11 \mathrm{q} 13.3$ renal cancer susceptibility locus influence binding of HIF to an enhancer of cyclin D1 expression. Nat Genet. 2012; 44:420-425, S421-422.

18. Henrion M, Frampton M, Scelo G, Purdue M, Ye Y, Broderick P, Ritchie A, Kaplan R, Meade A, McKay J, Johansson M, Lathrop M, Larkin J, Rothman N, Wang Z, Chow WH, et al. Common variation at 2q.3 (ZEB2) influences the risk of renal cancer. Hum Mol Genet. 2013; 22:825-831.

19. Heid IM, Jackson AU, Randall JC, Winkler TW, Qi L, Steinthorsdottir V, Thorleifsson G, Zillikens MC, Speliotes EK, Magi R, Workalemahu T, White CC, Bouatia-Naji N, Harris TB, Berndt SI, Ingelsson E, et al. Meta-analysis identifies 13 new loci associated with waisthip ratio and reveals sexual dimorphism in the genetic basis of fat distribution. Nat Genet. 2010; 42:949-960.

20. LeibundGut-Landmann S, Waldburger JM, Krawczyk M, Otten LA, Suter T, Fontana A, Acha-Orbea H, Reith W. Mini-review: Specificity and expression of CIITA, the master regulator of MHC class II genes. Eur J Immunol. 2004; $34: 1513-1525$. 
21. Dengjel J, Nastke MD, Gouttefangeas C, Gitsioudis G, Schoor O, Altenberend F, Muller M, Kramer B, Missiou A, Sauter M, Hennenlotter J, Wernet D, Stenzl A, Rammensee HG, Klingel K, Stevanovic S. Unexpected abundance of HLA class II presented peptides in primary renal cell carcinomas. Clin Cancer Res. 2006; 12:4163-4170.

22. Conde L, Halperin E, Akers NK, Brown KM, Smedby KE, Rothman N, Nieters A, Slager SL, Brooks-Wilson A, Agana L, Riby J, Liu J, Adami HO, Darabi H, Hjalgrim H, Low HQ, et al. Genome-wide association study of follicular lymphoma identifies a risk locus at 6p21.32. Nat Genet. 2010; 42:661-664.

23. Hakonarson H, Grant SF, Bradfield JP, Marchand L, Kim CE, Glessner JT, Grabs R, Casalunovo T, Taback SP, Frackelton EC, Lawson ML, Robinson LJ, Skraban R, Lu Y, Chiavacci RM, Stanley CA, et al. A genome-wide association study identifies KIAA0350 as a type 1 diabetes gene. Nature. 2007; 448:591-594.

24. Li X, Howard TD, Zheng SL, Haselkorn T, Peters SP, Meyers DA, Bleecker ER. Genome-wide association study of asthma identifies RAD50-IL13 and HLA-DR/DQ regions. J Allergy Clin Immunol. 2010; 125:328-335 e311.

25. Gorlova O, Martin JE, Rueda B, Koeleman BP, Ying J, Teruel M, Diaz-Gallo LM, Broen JC, Vonk MC, Simeon CP, Alizadeh BZ, Coenen MJ, Voskuyl AE, Schuerwegh AJ, van Riel PL, Vanthuyne $M$, et al. Identification of novel genetic markers associated with clinical phenotypes of systemic sclerosis through a genomewide association strategy. PLoS Genet. 2011; 7:e1002178.

26. Hor H, Kutalik Z, Dauvilliers Y, Valsesia A, Lammers GJ, Donjacour CE, Iranzo A, Santamaria J, Peraita Adrados R, Vicario JL, Overeem S, Arnulf I, Theodorou I, Jennum P, Knudsen S, Bassetti C, et al. Genome-wide association study identifies new HLA class II haplotypes strongly protective against narcolepsy. Nat Genet. 2010; 42:786-789.

27. Gharavi AG, Kiryluk K, Choi M, Li Y, Hou P, Xie J, Sanna-Cherchi S, Men CJ, Julian BA, Wyatt RJ, Novak J, He JC, Wang H, Lv J, Zhu L, Wang W, et al. Genomewide association study identifies susceptibility loci for IgA nephropathy. Nat Genet. 2011; 43:321-327.

28. Chen D, Juko-Pecirep I, Hammer J, Ivansson E, Enroth S, Gustavsson I, Feuk L, Magnusson PK, McKay JD, Wilander E, Gyllensten U. Genome-wide association study of susceptibility loci for cervical cancer. J Natl Cancer Inst. 2013; 105:624-633.

29. Jiang DK, Sun J, Cao G, Liu Y, Lin D, Gao YZ, Ren WH, Long XD, Zhang H, Ma XP, Wang Z, Jiang W, Chen TY, Gao Y, Sun LD, Long JR, et al. Genetic variants in STAT4 and HLA-DQ genes confer risk of hepatitis B virus-related hepatocellular carcinoma. Nat Genet. 2013; 45:72-75.

30. Olson SH, Kelsey JL, Pearson TA, Levin B. Evaluation of random digit dialing as a method of control selection in case-control studies. Am J Epidemiol. 1992; 135:210-222.

31. Wu X, Ye Y, Kiemeney LA, Sulem P, Rafnar T, Matullo G, Seminara D, Yoshida T, Saeki N, Andrew AS, Dinney CP,
Czerniak B, Zhang ZF, Kiltie AE, Bishop DT, Vineis P, et al. Genetic variation in the prostate stem cell antigen gene PSCA confers susceptibility to urinary bladder cancer. Nat Genet. 2009; 41:991-995.

32. Beroukhim R, Brunet JP, Di Napoli A, Mertz KD, Seeley A, Pires MM, Linhart D, Worrell RA, Moch H, Rubin MA, Sellers WR, Meyerson M, Linehan WM, Kaelin WG Jr., Signoretti S. Patterns of gene expression and copy-number alterations in von-hippel lindau disease-associated and sporadic clear cell carcinoma of the kidney. Cancer Res. 2009; 69:4674-4681.

33. Gumz ML, Zou H, Kreinest PA, Childs AC, Belmonte LS, LeGrand SN, Wu KJ, Luxon BA, Sinha M, Parker AS, Sun LZ, Ahlquist DA, Wood CG, Copland JA. Secreted frizzled-related protein 1 loss contributes to tumor phenotype of clear cell renal cell carcinoma. Clin Cancer Res. 2007; 13:4740-4749.

34. Higgins JP, Shinghal R, Gill H, Reese JH, Terris M, Cohen RJ, Fero M, Pollack JR, van de Rijn M, Brooks JD. Gene expression patterns in renal cell carcinoma assessed by complementary DNA microarray. Am J Pathol. 2003; 162:925-932.

35. Jones J, Otu H, Spentzos D, Kolia S, Inan M, Beecken WD, Fellbaum C, Gu X, Joseph M, Pantuck AJ, Jonas D, Libermann TA. Gene signatures of progression and metastasis in renal cell cancer. Clin Cancer Res. 2005; 11:5730-5739.

36. Lenburg ME, Liou LS, Gerry NP, Frampton GM, Cohen HT, Christman MF. Previously unidentified changes in renal cell carcinoma gene expression identified by parametric analysis of microarray data. BMC Cancer. 2003; 3:31.

37. Yusenko MV, Kuiper RP, Boethe T, Ljungberg B, van Kessel AG, Kovacs G. High-resolution DNA copy number and gene expression analyses distinguish chromophobe renal cell carcinomas and renal oncocytomas. BMC Cancer. 2009; 9:152.

38. Yang TP, Beazley C, Montgomery SB, Dimas AS, Gutierrez-Arcelus M, Stranger BE, Deloukas P, Dermitzakis ET. Genevar: a database and Java application for the analysis and visualization of SNP-gene associations in eQTL studies. Bioinformatics. 2010; 26:2474-2476.

39. Nica AC, Parts L, Glass D, Nisbet J, Barrett A, Sekowska M, Travers M, Potter S, Grundberg E, Small K, Hedman AK, Bataille V, Tzenova Bell J, Surdulescu G, Dimas AS, Ingle $\mathrm{C}$, et al. The architecture of gene regulatory variation across multiple human tissues: the MuTHER study. PLoS Genet. 2011; 7:e1002003.

40. Chen M, Ye Y, Yang H, Tamboli P, Matin S, Tannir NM, Wood CG, Gu J, Wu X. Genome-wide profiling of chromosomal alterations in renal cell carcinoma using high-density single nucleotide polymorphism arrays. Int J Cancer. 2009; 125:2342-2348.

41. Ward LD, Kellis M. HaploReg: a resource for exploring chromatin states, conservation, and regulatory motif 
alterations within sets of genetically linked variants. Nucleic Acids Res. 2012; 40:D930-934.

42. Boyle AP, Hong EL, Hariharan M, Cheng Y, Schaub MA, Kasowski M, Karczewski KJ, Park J, Hitz BC, Weng S, Cherry JM, Snyder M. Annotation of functional variation in personal genomes using RegulomeDB. Genome Res. 2012; 22:1790-1797.

43. A user's guide to the encyclopedia of DNA elements (ENCODE) . PLoS Biol. 2011; 9:e1001046.

44. Wang K, Li M, Bucan M. Pathway-based approaches for analysis of genomewide association studies. Am J Hum Genet. 2007; 81:1278-1283.

45. O'Dushlaine C, Kenny E, Heron EA, Segurado R, Gill M, Morris DW, Corvin A. The SNP ratio test: pathway analysis of genome-wide association datasets. Bioinformatics. 2009; 25:2762-2763.

46. Holmans P, Green EK, Pahwa JS, Ferreira MA, Purcell SM, Sklar P, Owen MJ, O’Donovan MC, Craddock N. Gene ontology analysis of GWA study data sets provides insights into the biology of bipolar disorder. Am J Hum Genet. 2009; 85:13-24.

47. Price AL, Patterson NJ, Plenge RM, Weinblatt ME, Shadick NA, Reich D. Principal components analysis corrects for stratification in genome-wide association studies. Nat Genet. 2006; 38:904-909.

48. Liu JZ, McRae AF, Nyholt DR, Medland SE, Wray NR, Brown KM, Hayward NK, Montgomery GW, Visscher PM, Martin NG, Macgregor S. A versatile gene-based test for genome-wide association studies. Am J Hum Genet. 2010; 87:139-145.

49. Howie B, Marchini J, Stephens M. Genotype imputation with thousands of genomes. G3 (Bethesda). 2011; 1:457-470.

50. Howie B, Fuchsberger C, Stephens M, Marchini J, Abecasis GR. Fast and accurate genotype imputation in genome-wide association studies through pre-phasing. Nat Genet. 2012; 44:955-959. 